\title{
VARIATION IN WILD POPULATIONS OF PAPAVER DUBIUM
}

\section{DOMINANCE RELATIONSHIPS FOR GENES CONTROLLING METRICAL CHARACTERS}

\author{
A. E. ARTHUR*, M. S. RANA, J. S. GALE, M. O. HUMPHREYS and \\ M. J. LAWRENCE \\ Department of Genetics, University of Birmingham, Birmingham B15 2TT
}

Received 10.iv.72

\section{SUMMARY}

Evidence is presented which suggests that genes controlling the juvenile characters leaf number and diameter and perhaps also elevation of the outermost leaf exhibit directional dominance, but that this dominance is probably very incomplete. The same probably holds for genes controlling flowering time. Dominance for these characters is in the direction which would be expected if plants with rapid development were at a selective advantage. The data on juvenile height are consistent with this idea. The fact that dominance seems to be incomplete, however, suggests that the optimum rate of development is not at the extreme of the range. This may be related to the observation that a considerable proportion of seeds germinate well before the growing season. Genes controlling the number of stigmatic rays exhibited very little potence, indicating that any selection on this character is of the stabilising type. Genes controlling capsule number, which is known to be an important component of fitness, show directional dominance for increased capsule number. The level of dominance in this case is probably high, since heterosis for this character was found in nearly all cases.

\section{INTRODUCTION}

IN earlier papers in this series (Lawrence, 1965, 1972; Gale and Arthur, 1972; Gale and Eaves, 1972) it was shown that, out of 18 characters studied, 14 show genetic variation within at least some of the populations studied. In the case of the character we have studied most intensively, namely flowering time, 17 out of 18 natural populations exhibited this type of variation. We have, as yet, no reliable estimates of the type or intensity of selection that might be operating on these characters. However, over a number of years, we have collected information on the genetics of a number of these characters. From these results we shall attempt to draw tentative inferences on the type of selection that has been operating on these characters in the past.

\section{Materials AND MEthods}

Our sources of information are as follows. Firstly, we have the intrapopulation diallel sets of crosses described by Lawrence $(1965,1972)$. These were carried out on material obtained from five populations; plants were scored for flowering time, stigmatic ray number, final height and capsule number. The last character did not exhibit genetic variation within any of these five populations. Secondly, we have the results of crosses carried out

* Present address: John Innes Institute, Colney Lane, Norwich NOR 70F. 
on material obtained from the six natural populations discussed by Gale and Arthur (1972). For these populations we have the results of diallel sets of crosses between plants raised from seed collected from the wild. As we shall discuss later, these were scored for juvenile height, diameter, elevation and leaf number. In addition, we have the results of augmented biparental matings (Kearsey, 1970) between partially inbred lines derived from the same wild material. The progenies of these matings were raised by Mr F. G. Bassi for another purpose, but we have scored them for capsule number, since this character was known to exhibit genetic variation in these populations (Hawker, personal communication), whereas in the populations studied earlier by Lawrence, no such variation was detected for this character.

Details are as follows. Seed was collected from our six natural populations in 1965. Each population was sampled at fortnightly intervals. In order to obtain an (approximately) random sample, all capsules ripe at the time of collection were gathered, except for one population, Wellesbourne, which was too large for this procedure to be practicable. For this population, which stretched for about two miles along a roadside verge, we sampled by walking the length of the population, stopping every few yards and taking a ripe capsule from the nearest plant on which such a capsule was present.

Plants were grown in the experimental field in 1966, eight plants being raised from every capsule collected. From every population, 16 such plants were taken at random. It was intended to make up two separate $8 \times 8$ diallel sets of crosses in every population. It may be helpful to explain briefly why this attempt was not entirely successful, since the problems encountered were due in part to the fact that we were working with plants raised from seed collected from the wild. One factor was the exceptionally wet weather in 1966, which made pollinating extremely difficult. As a result, a number of crosses failed and some plants died before the crossing programme was complete. The premature death of these plants was usually associated with chlorosis, a condition often found when plants derived from wild seed are grown in the experimental field. A further difficulty was that some of the plants obtained from one population, Henley, turned out not to be Papaver dubium, although bearing a resemblance to it. These plants, in fact, seem not to belong to any species regularly occurring in Britain.

We have decided, therefore, to exclude from the data all crosses involving these unusual Henley plants and also arrays in which either the selfs failed or in which many crosses failed. This leaves us with the following diallel sets of crosses:

$\begin{array}{ll}\text { Henley } & 5 \times 5,6 \times 6 \\ \text { Wellesbourne } & 6 \times 6,7 \times 7 \\ \text { Luddington } & 8 \times 8,7 \times 7 \\ \text { Welford } & 8 \times 8,7 \times 7 \\ \text { Blakedown } & 8 \times 8,7 \times 7 \\ \text { University } & 7 \times 7,7 \times 7\end{array}$

It was intended to raise progenies in two randomised blocks, sown one week apart, four sibs from every family in each block, and to score plants for juvenile height, diameter, elevation and leaf number, the blocks being scored one week apart. Attempts to score characters at flowering time were badly upset by bird damage to flowers and by the tendency of the first flower to abort in many cases. We are unable to account for the latter phenomenon, 
which is much less common in other seasons. We shall, therefore, confine ourselves here to the juvenile characters. Even for these, there were a considerable number of missing plots. To allow for these, all analyses were carried out on family means in each block and the error mean square divided by the harmonic mean of the number of observations for every family in each block, in the usual way. More difficult to allow for are completely missing families and our allowances for these are inevitably rather crude. We first carried out, for each character, a two-way analysis of variance for blocks and (all) families, making due allowance for unequal numbers (see $e . g$. Snedecor and Cochran, 1967). This analysis showed that there were no significant block interactions. This enabled us to cope with cases where a family was missing in one block only, since the missing value could be replaced by the mean for the same family in the other block, adjusted by the estimated difference between blocks for the character under consideration. If a family was missing in both blocks, the procedure was a little more complicated. In some cases, the family was known to be missing from the start, owing to obvious poor quality of seed. In other cases, however, the family was not recognised as missing until the seed failed to germinate or establish. In the first case, seed from the reciprocal family was sown, so that the reciprocal family appeared twice. This is reasonably satisfactory provided some adjustment can be made for maternal effects, if any. Suppose a cross $A \times B$ is missing and instead we have sown $B \times A$. We consider, for the block concerned, the arrays with $A$ as female parent and $A$ as male parent; if a cross is missing in one array, we exclude its reciprocal in the other array. We now calculate, for a given character, the average performance for both arrays, averages being taken on family means. The difference between average performance in the two arrays is an estimate of the consistent maternal effect of $A$. In cases, however, where the reciprocal was not sown to replace the missing family, we had no choice but to adjust the mean of the reciprocal family in the same block. These adjustments are necessary only if maternal effects are present. This was tested for, diallel by diallel, by calculating a mean square for reciprocal differences, ignoring families where one reciprocal was absent. Obviously, the absence of many plots detracts from the value of the data and the corrections applied, although reasonable, are not entirely satisfactory; although some alterations should be made to degrees of freedom for the various items in the analysis of variance in order to compensate for the effects of adjustments, there seems to be no way in which this can be done. However, provided we confine ourselves to general features of the diallel table, such as average potence, we are unlikely to go far astray.

The augmented biparental matings presented no serious problems. The basic material consisted of (partially) inbred lines, each originating from a different wild plant. The lines had a history of four generations of selfing. No plants from Henley were used, for reasons to be discussed below. In each of the other populations, a single plant was taken from each line and plants paired up at random. In every pair, plants were selfed and crossed reciprocally. We shall refer to a group of four progenies resulting from such a pair as a " set". In all, there were 19 sets, with origin as follows, the number of sets in each population being indicated in parentheses:

Wellesbourne (4), Luddington (4), Welford (2), Blakedown (5), University (4). 
From every family, 25 sibs, taken at random, were scored for capsule number.

\section{Analysis of diallel data in the six populations}

The diallel data were analysed using the analysis of variance given by Hayman (1954). An example is shown in table 1. As block interactions were not significant, these were pooled, for each diallel set, with the within family variance for that diallel set, to give the error mean square.

TABLE 1

Analysis of variance of diameter in the first Welford diallel set

\section{Item}

(a) Additive variation Non-additive variation:

$\left(b_{1}\right)$ Average potence

$\left(b_{2}\right)$ Potence $\times$ arrays

$\left(b_{3}\right)$ Residual non-additive variation

(c) Consistent maternal effects

(d) Random reciprocal differences Blocks Error

$$
\begin{array}{r}
\text { d.f. } \\
7 \\
1 \\
7 \\
20 \\
7 \\
21 \\
1 \\
424
\end{array}
$$$$
7
$$$$
1
$$$$
20
$$$$
7
$$

$\begin{array}{rr}\text { M.S. } & \text { V.R. } \\ 2511.3972 & 13.64 \\ & \\ 249.6025 & 1.36 \\ 188 \cdot 0648 & 1.02 \\ 587 \cdot 1673 & 3 \cdot 19 \\ 125 \cdot 1500 & 0.68 \\ 309.0614 & 1.68 \\ 10190.0303 & 55.34 \\ 184.1399 & -\end{array}$

$\mathbf{P}$ $\ll 0 \cdot 1 \%$ $>20 \%$ $>20 \%$ $<0 \cdot 1 \%$ n.s. $5 \%-2 \%$ $\ll 0 \cdot 1 \%$

To preserve comparability between different diallels, all mean squares were tested against the error mean square. Full details of these analyses are available on request.

\section{A population with little heritable Variation}

The Henley population presented unusual features. We shall, therefore, consider this population first. No significant additive variation was detected, in either diallel set, for leaf number, height or diameter. For these characters, mean squares measuring non-additive effects were also not significant, apart from one case. Moreover, we have evidence that there is little heritable variation for flowering time in this population. When the original wild seed was collected, different capsules were kept separate; we shall use the term " family" for a group of plants derived from seed from the same capsule. When, as described earlier, plants raised from the wild seed were grown in 1966, they were scored for flowering time. In contrast to plants from the other populations, Henley plants showed no significant differences between "families"; the estimated proportion of total variance between plants attributable to between " families" effects being only 6 per cent. in contrast to the values 35 to 51 per cent. for the other populations.

Only for elevation do we have evidence of heritable variation in this population; the $(a)$ mean square was significant in both diallel sets. Mean squares for non-additive effects were not significant except for $\left(b_{1}\right)$ in one diallel set only.

If additive variation were at all substantial, it should easily be detected. It follows that heritable variation in this population is almost certainly very low. This is not surprising since the population was very small, comprising about 30 to 40 plants. The lack of heritable variation could be due to founder effect or subsequent random extinction. 


\section{Maternal EFFECTS}

We now turn to the other five populations and consider first possible maternal effects. The $(c)$ mean square in Hayman's analysis measures maternal effects which are consistent over all crosses within an array. These (c) effects reached significance in five cases only, namely for height in one Luddington and one Welford diallel set and for elevation in both Welford diallel sets and one University diallel set. Thus, although maternal effects are present, at least in some cases, consistent maternal effects are probably feeble.

The $(d)$ mean square measures differences between reciprocals not accounted for by $(c)$ effects. In addition to genuine maternal effects, any result of storing seed of different families in different packets, slight differences in the time of exposure of seed of different families to the sulphuric acid used to induce germination or the fact that after acid treatment seed of different

TABLE 2

Mean potence for each diallel set

$\begin{array}{cccccc}\text { Diallel set } & & \begin{array}{c}\text { Leaf } \\ \text { number }\end{array} & \begin{array}{c}\text { Height } \\ (\mathrm{mm} .)\end{array} & \begin{array}{c}\text { Diameter } \\ (\mathrm{mm} .)\end{array} & \begin{array}{c}\text { Elevation } \\ \text { (degrees) }\end{array} \\ \text { Wellesbourne } & 1 & 0.73^{*} & -2.85 & 23.30^{* * *} & -5.78^{* * *} \\ & 2 & 0.28 & -4.92 * * * & 12.00^{*} & -3.85^{* * *} \\ \text { Luddington } & 1 & 0.21 & -1.33 & 4.54 & -2.25 \\ & 2 & 0.38 & -0.07 & 3.39 & -0.23 \\ \text { Welford } & 1 & 0.26 & -4.49 * * * & 4.22 & 0.23 \\ & 2 & -0.10 & 1.69 & 0.28 & -0.35 \\ \text { Blakedown } & 1 & 0.51 & 3.01 & 18.60^{* *} & -1.08 \\ & 2 & 0.65 & -2.94 & 23.49 * * * & -4.41 \\ \text { University } & 1 & 0.52 & 0.25 & 6.24 & 0.93 \\ & 2 & 0.26 & 2.55 & 6.69 & -0.88\end{array}$

families was kept in different petri dishes in different (random) positions in the incubator until seed had germinated, will inflate $(d)$. Such technical errors do not contribute to the error mean square, since seeds were not individually randomised until they were sown. In practice, out of a possible 40,10 of the $(d)$ mean squares proved to be significant. This sets an upper limit to the number of significant random reciprocal differences attributable to a genuine maternal effect. We are probably justified in concluding that, for the characters studied, maternal effects are weak.

\section{Dominance: juVEnile characters AND Flowering time}

We now consider possible dominance effects. Here, as we shall see, our conclusions will be very tentative. Our main interest is whether or not dominance is directional. In table 2 , we give values, for every character in every diallel set, of average potence, that is, the overall mean of outcross progenies less the overall mean of self-progenies. The $\left(b_{1}\right)$ item in the analysis of variance tests whether average potence differs significantly from zero; we indicate significance levels in table 2. 
In order to put these potence values in perspective, we give in table 3 the range of variation of the means of self-progenies.

Significant mean potence indicates the presence of directional dominance or perhaps directional epistasis in the population under study. In the present context, however, the distinction between directional dominance and directional epistasis is unimportant, since either phenomenon would give rise to the same conclusion with regard to the type of natural selection which has been operating on the character concerned. Since it is extremely unlikely that directional epistasis would be present unless directional dominance were also present, we shall for brevity ascribe significant mean potence to the effect of directional dominance, it being understood that some directional epistasis may also be present.

TABLE 3

Difference between largest and smallest family mean among self families

$\begin{array}{lccccc}\text { Diallel } & & \begin{array}{c}\text { Leaf } \\ \text { number }\end{array} & \begin{array}{c}\text { Height } \\ (\mathrm{mm} .)\end{array} & \begin{array}{c}\text { Diameter } \\ (\mathrm{mm} .)\end{array} & \begin{array}{c}\text { Elevation } \\ \text { (degrees) }\end{array} \\ \text { Wellesbourne } & 1 & 2.25 & 15.63 & 44.37 & 17.08 \\ & 2 & 4.59 & 18.33 & 39.17 & 18.34 \\ \text { Luddington } & 1 & 5.25 & 22.50 & 60.00 & 19.37 \\ & 2 & 4.00 & 11.25 & 32.50 & 8.34 \\ \text { Welford } & 1 & 2.37 & 31.25 & 58.75 & 27.50 \\ & 2 & 2.87 & 15.00 & 67.50 & 18.75 \\ \text { Blakedown } & 1 & 3.87 & 90.00 & 65.62 & 31.25 \\ & 2 & 2.63 & 47.29 & 46.87 & 19.38 \\ \text { University } & 1 & 1.63 & 13.12 & 37.50 & 8.12 \\ & 2 & 2.62 & 8.75 & 34.37 & 9.37\end{array}$

Now is is apparent from table 2 that very few of the mean potences are significant. It does not necessarily follow from this that directional dominance is weak. If, for a given character, the frequencies of the increasing and decreasing alleles at the $i$ th locus are $u, v$ and the corresponding dominance effect is $h$, then (Kearsey, 1970) in the absence of epistasis the average potence is an estimate of

$$
\sum_{\text {loci }}(1+f) u v h
$$

where $f$ is the empirical inbreeding coefficient. Hence with very unequal frequencies of increasers as compared with decreasers, mean potence will be small.

However, it is clear from table 2 that the direction of average potence shows consistency over diallel sets for both leaf number and diameter. On testing the null hypothesis that positive and negative values are equally common, we find $\mathrm{P}=2$ per cent. for leaf number and $\mathrm{P}=0.2$ per cent. for diameter. Moreover, the majority of individual crosses show, for either character, potence in the upward direction. For example, in the Wellesbourne population, where the mean potence for leaf number averaged over both diallel sets is 0.51 , we found that in 24 cases out of a possible 36 the mean leaf number of outcross progeny exceeded the mean leaf number of the corresponding selfed progenies averaged together. In other words, the direction 
of mean potence for a given diallel table is a fair reflection of the direction of potence for most of the individual crosses within the table and is not due to the presence of a few unusual crosses showing a high degree of directional potence.

Thus, in spite of the small number of significant $\left(b_{1}\right)$ items, there can be no serious doubt that both characters show dominance in the upward direction. The elevation data are not so clear cut; although eight out of 10 potences are negative, this does not depart significantly from equality $(\mathbf{P}=11$ per cent.). For Wellesbourne, Luddington and Blakedown, a large majority of individual crosses show the downward potence. In the other two populations, about as many crosses show upward potence as downward. On averaging over both diallel sets, we find the overall mean potence for elevation, as given in table 4 , to be -0.06 in one of these two populations, 0.03 in the other. Thus, whereas for leaf number and diameter the direction of dominance is upwards in all populations, in the case of elevation we have evidence for directional dominance in three populations only; in these cases dominance is downwards. The height data will be considered later.

We now turn to the actual magnitude of dominance. A possible clue to this comes from simulation studies on diallels carried out by $\mathrm{Dr}$ M. J. Kearsey and Dr B. W. Barnes (personal communication). The results

TABLE 4

Overall mean potence for each population

$\begin{array}{lcccc}\text { Population } & \begin{array}{c}\text { Leaf } \\ \text { number }\end{array} & \text { Height } & \text { Diameter } & \text { Elevation } \\ \text { Wellesbourne } & 0.51 & -3.89 & 17.70 & -4.82 \\ \text { Luddington } & 0.30 & -0.70 & 3.97 & -1.24 \\ \text { Welford } & 0.08 & -1.40 & 2.25 & -0.06 \\ \text { Blakedown } & 0.58 & 0.04 & 21.05 & -2.25 \\ \text { University } & 0.39 & 1.40 & 6.47 & 0.03\end{array}$

suggest that, if directional dominance is strong, the $\left(b_{1}\right)$ item in Hayman's analysis will be significant on many more occasions than $\left(b_{2}\right)$ or $\left(b_{3}\right)$. Moreover, the $\left(b_{1}\right)$ mean square is almost always larger than either the $\left(b_{2}\right)$ or $\left(b_{3}\right)$ mean square. Now, neither for leaf number nor diameter were these the case. For example, the diameter results gave four significant $\left(b_{1}\right)$, three significant $\left(b_{2}\right)$ and six significant $\left(b_{3}\right)$. The $\left(b_{1}\right)$ mean square was greater than the $\left(b_{2}\right)$ in six cases, less in four. The $\left(b_{1}\right)$ mean square was greater than the $\left(b_{3}\right)$ in four cases, less in six.

Thus we may draw the tentative conclusion for these characters that, while dominance in the upward direction exists, dominance is by no means complete. Perhaps the same holds for elevation in at least some of our populations, with doninance, however, in the downward direction.

If we interpret our results in accordance with the ideas of Mather (1960), we conclude that selection for both leaf number and diameter has been in the upward direction. Since, however, dominance is apparently incomplete, if follows that while selection is directional in the sense that the optimum phenotype lies above the population mean, on the other hand the optimum does not lie at the extreme of the phenotypic range. The extent to which the optimum exceeds the population mean may well vary from one population to another. In the case of elevation, our results suggest that the optimum lies below the population mean in at least some populations. 
Now leaf number, diameter and elevation may all be regarded as aspects of rate of plant growth. As the plant develops, leaf number and diameter increase and elevation, which it will be recalled is the angle between the outermost leaf and the horizontal, decreases. Height presents a paradoxical picture (Gale and Eaves, 1972). At an early seedling stage, the height of the plant is, in fact, the height of the outermost leaves. Subsequently, these become less elevated and lie almost horizontally. Thus, in the course of development, plant height falls, only to rise again as the crown leaves develop.

Suppose then that we have had, in the past, directional selection for rapid juvenile development. In so far as our four characters represent different aspects of the rate of development, we would expect to find directional dominance upwards for leaf number and diameter, downwards for elevation. For height, the picture would change during development; during the early phase, when height is falling, we expect dominance to be downwards, whereas later, when height is rising, dominance would be upwards. Unfortunately, at the time when measurements were made, we were unaware of the detailed pattern of changes in height during development and so did not record which part of the plant was tallest at the time of measurement; certainly some but by no means all plants were in the upward phase at this time, but we have no details on this. However, we have observed on a number of occasions that Blakedown and University plants develop; on average, well ahead of plants from the other populations, whereas Wellesbourne plants are the slowest. It is interesting, therefore, to note that, as will be seen from table 4, potence for height is upwards in Blakedown and University plants and downwards in the other cases.

Evidence suggests (Gale and Arthur, 1972; Gale and Eaves, 1972) that all four of our characters are, to some extent, controlled by the same set of loci. These loci also affect flowering time. In the five populations studied by Lawrence (1965), average potence for flowering time was in the direction of earliness in all populations, although, as in the present case, the $\left(b_{1}\right)$ mean square in Hayman's analysis was not always significant.

Our data, then, are consistent with the view that, in the past, there has been natural selection for rapid development, the intensity of selection varying somewhat from one population to another, and that the effects of this selection are reflected in mean potence values for all five characters. It need hardly be stressed that we need more precise estimates of potence; these would best be obtained from augmented biparental matings on pairs of inbred lines, where the lines comprising a pair were derived from the same population. We have now obtained lines with a history of eight successive selfings and the experiment suggested is in progress.

It is, of course, expected that plants showing rapid development during the growth season would be at a selective advantage, owing to their superior competitive ability. On the other hand, our observations over two years on an artificial population, in which conditions were similar to the natural ones, indicate that, in nature, about 40 per cent. of the plants which constitute the adult population are already present as seedlings by the end of February in at least some populations in some years. This would explain our finding that the optimum is not at the extreme of the range; plants with a genotype conferring very rapid development might develop prematurely if conditions were temporarily mild. In practice, rapid growth begins towards the end of April. 


\section{Dominance: Stigmatic Rays}

We now turn to the data on number of stigmatic rays and on final height (Lawrence, 1972). Stigmatic ray number presented very little evidence of dominance of any kind. In three populations, average potence was negative, in two positive. We may conclude that any selection operating on this character is of the stabilising type. The data on final height presented many difficulties and it seems best to postpone discussion on this character until more data are available.

\section{Dominance: GAPSUle NUMBer}

Finally, we consider capsule number. For this character we have direct evidence of the direction of selection. It is natural to suppose that seed output per plant increases as the number of capsules increases. In principle,

TABLE 5

Number of seeds produced in various capsules

Number of capsules Number of per plant

$\begin{array}{rrrrrrrrrrr}\text { plant } & \text { plants } & 1 & 3 & 5 & 7 & 9 & 11 & 13 & 15 & 17 \\ 1 & 2 & 6 & - & - & - & - & - & - & - & - \\ 2 & 14 & 370 & - & - & - & - & - & - & - & - \\ 3 & 11 & 528 & 201 & - & - & - & - & - & - & - \\ 4 & 22 & 581 & 235 & - & - & - & - & - & - & - \\ 5 & 27 & 644 & 342 & 236 & - & - & - & - & - & - \\ 6 & 16 & 653 & 380 & 239 & - & - & - & - & - & - \\ 7 & 14 & 867 & 379 & 305 & 205 & - & - & - & - & - \\ 8 & 6 & 1174 & 514 & 440 & 227 & - & - & - & - & - \\ 9 & 3 & 1162 & 770 & 762 & 502 & 190 & - & - & - & - \\ 12 & 3 & 1552 & 934 & 609 & 202 & 208 & 154 & - & - & - \\ 17 & 2 & 1727 & 1431 & 824 & 729 & 1450 & 808 & 229 & 448 & 262\end{array}$

Mean number of seeds in capsule indicated

however, there is the possibility that a plant with many capsules has fewer seeds per capsule than a plant with few capsules. However, we have shown, at least for one population, that such compensation does not occur. The experiment was carried out, in 1965, on the artificial population mentioned above. A random sample of plants was taken and capsule number recorded; however, we shall ignore throughout capsules appearing on flowers opening after 8th September, since these capsules did not contain viable seed. The first, third, fifth, etc. flowers to open were allowed to open-pollinate and we have seed counts for capsules from these. The other flowers were selfed for another purpose and seed counts from these would have little meaning. Results are given in table 5. It is apparent that seed output per plant rises steeply as the number of capsules per plant increases.

The results for the augmented biparental matings are given in table 6, all means being based on 25 plants.

It will be seen that, in 16 out of the 19 sets, the mean of the outcross progenies is greater than the mean of the higher yielding self-progeny, sometimes marginally, but sometimes strikingly so. In the three cases where this heterosis is not found, outcross progenies still perform very much better than the mean of the corresponding self-progenies.

Average potences for the different populations are given in table 7 . 
A formal analysis of these results is scarcely necessary, but we have included an example in order to illustrate the difference between the situation for capsule number and that for the other characters. This example is given in table 8; we have omitted the item for between sets as being of little

TABLE 6

Mean capsule numbers in progenies from augmented biparental matings

$\begin{array}{lccccc}\text { Population } & \text { Set } & \bar{P}_{1} & \bar{P}_{2} & \bar{F}_{1}, \bar{F}_{1}^{\prime} & \frac{1}{2}\left(\bar{F}_{1}+\bar{F}_{1}^{\prime}\right) \\ \text { Wellesbourne } & 1 & 50 \cdot 76 & 26 \cdot 44 & 54 \cdot 08,54 \cdot 28 & 54 \cdot 18 \\ & 2 & 52 \cdot 08 & 41 \cdot 64 & 61 \cdot 80,59 \cdot 36 & 60 \cdot 58 \\ & 3 & 53 \cdot 36 & 46 \cdot 20 & 71 \cdot 44,62 \cdot 20 & 66 \cdot 82 \\ \text { Luddington } & 4 & 59 \cdot 12 & 51 \cdot 72 & 72 \cdot 24,85 \cdot 16 & 78 \cdot 70 \\ & 1 & 37 \cdot 96 & 31 \cdot 28 & 44 \cdot 08,41 \cdot 12 & 42 \cdot 60 \\ & 2 & 51 \cdot 24 & 30 \cdot 24 & 49 \cdot 36,56 \cdot 28 & 52 \cdot 82 \\ \text { Welford } & 3 & 88 \cdot 44 & 59 \cdot 20 & 92 \cdot 52,69 \cdot 56 & 81 \cdot 04 \\ & 4 & 49 \cdot 76 & 35 \cdot 96 & 44 \cdot 96,51 \cdot 24 & 48 \cdot 10 \\ \text { Blakedown } & 1 & 45 \cdot 72 & 44 \cdot 60 & 57 \cdot 20,41 \cdot 16 & 49 \cdot 18 \\ & 2 & 47 \cdot 84 & 45 \cdot 04 & 67 \cdot 20,62 \cdot 28 & 64 \cdot 74 \\ & 1 & 55 \cdot 40 & 51 \cdot 20 & 72 \cdot 40,69 \cdot 28 & 70 \cdot 84 \\ & 2 & 59 \cdot 60 & 42 \cdot 20 & 73 \cdot 40,68 \cdot 80 & 71 \cdot 10 \\ \text { University } & 3 & 45 \cdot 04 & 41 \cdot 48 & 50 \cdot 64,56 \cdot 96 & 53 \cdot 80 \\ & 4 & 66 \cdot 56 & 61 \cdot 96 & 63 \cdot 68,69 \cdot 96 & 66 \cdot 82 \\ & 5 & 55 \cdot 72 & 38 \cdot 28 & 57 \cdot 48,65 \cdot 68 & 61 \cdot 58 \\ & 1 & 50 \cdot 16 & 26 \cdot 68 & 51 \cdot 64,49 \cdot 04 & 50 \cdot 34 \\ & 2 & 73 \cdot 52 & 49 \cdot 40 & 74 \cdot 52,85 \cdot 08 & 79 \cdot 80 \\ & 3 & 55 \cdot 76 & 54 \cdot 08 & 72 \cdot 48,66 \cdot 24 & 69 \cdot 36 \\ & 4 & 61 \cdot 48 & 53 \cdot 32 & 58 \cdot 68,62 \cdot 52 & 60 \cdot 60\end{array}$

$P_{1}, \vec{P}_{2}=$ Means of progenies of parents selfed (progeny with greater mean written first). $\bar{F}_{1}, \bar{F}_{1}^{\prime}=$ Means of progenies of reciprocal crosses.

TABLE 7

Mean potence for capsule number

$\begin{array}{lcc}\text { Population } & \text { Mean potence } & \begin{array}{c}\text { Potence ratio } \\ \text { averaged over sets }\end{array} \\ \text { Wellesbourne } & 17 \cdot 41 & 3 \cdot 74 \\ \text { Luddington } & 8 \cdot 13 & 1 \cdot 20 \\ \text { Welford } & 11 \cdot 16 & 10 \cdot 13 \\ \text { Blakedown } & 13 \cdot 08 & 3 \cdot 88 \\ \text { University } & 11 \cdot 98 & 5 \cdot 13 \\ & & \end{array}$

Analysis of capsule number data from the University population

\begin{tabular}{lrrrc}
$\quad$ Item & d.f. & \multicolumn{1}{c}{ M.S. } & V.R. & P \\
Within sets: & & & & \\
$\quad$ Between parents & 4 & $3757 \cdot 7900$ & $5 \cdot 01$ & $<0 \cdot 1 \%$ \\
Between reciprocal crosses & 4 & 537.3650 & $<1$ & n.s. \\
Average potence & 1 & 14340.0600 & $19 \cdot 13$ & $<0.1 \%$ \\
Potence $\times$ sets & 3 & 1029.9433 & $1 \cdot 37$ & $>20 \%$ \\
Within families & 384 & 749.6573 & &
\end{tabular}

interest. In no population was potence $\times$ sets significant, so that the withinfamilies mean square is the appropriate error for testing average potence, as well as for the other items. Average potence was highly significant in all populations. However, of greater interest is the general occurrence, noted 
above, of heterosis. We have a marked degree of directional dominance that is, the classical picture for components of fitness (Mather, 1960; Kearsey and Kojima, 1967).

Apart from one doubtful case, maternal effects are absent, as is not surprising for a character scored at the end of the season.

Acknowledgments.-We are indebted to a number of past and present members of the department, in particular Dr J. H. Croft, Dr M. J. Kearsey and Mr M. G. Freeman, for assistance in collecting wild material and to the late $\mathrm{Mr} \mathrm{E}$. Jama for technical assistance. We should also like to thank Professor J. L. Jinks and Dr Kearsey for very helpful discussions. The diallel analyses were carried out on the KDF 9 computer at Birmingham University. This work was supported by the Agricultural Research Council and research studentships given by the Science Research Council.

\section{REFERENCES}

GALE, J. S., AND ARTHUR, A. E. 1972. Variation in wild populations of Papaver dubium. IV. A survey of variation. Heredity, 28, 91-100.

GALE, J. S., AND EAVEs, L. J. 1972. Variation in wild populations of Papaver dubium. V. The application of factor analysis to the study of variation. Heredity, 29, 135-149.

HAYMAN, в. r. 1954. The analysis of variance of diallel tables. Biometrics, 10, 235-244.

KEARSEY, M. J. 1970. Experimental sizes for detecting dominance variation. Heredity, 25, 529-542.

KEARSEY, M. J., AND KOJIMA, K. 1967. The genetic architecture of body weight and egg hatchability in Drosophila melanogaster. Genetics, 56, 23-37.

LAWRENCE, M. J. 1965. Variation in wild populations of Papaver dubium. I. Variation within populations; diallel crosses. Heredity, 20, 183-204.

LAWRENCE, M. J. 1972. Variation in wild populations of Papaver dubium. III. The genetics of stigmatic ray number, height and capsule number. Heredity, 28, 71-90.

Mather, x. 1960. Evolution in polygenic systems. Int. Colloquium on Evolution and Genetics, 131-152. Rome. Accad. Naz. dei Lincei.

SNEDECOR, G. W., AND COCHRAN, w. G. 1967. Statistical Methods. Iowa State University Press. 